\title{
Psychopathological factors, memory disorders and transient global amnesia
}

Audrey Noël, Peggy Quinette, Bérengère Guillery-Girard, Jacques Dayan, Pascale Piolino,

Sophie Marquis, Vincent de la Sayette, Fausto Viader, Béatrice Desgranges and Francis Eustache

\section{Background}

Some studies have shown the presence of psychopathological disorders in transient global amnesia.

\section{Aims}

To determine whether transient global amnesia is associated with psychopathological disorders and to assess the influence of these psychopathological disorders on memory impairments.
Method
Levels of anxiety and depression before and during transient global amnesia were rated. Memory performances were assessed by means of original episodic memory tasks and working memory tasks. These data were collected in 17 individuals observed during the very acute phase, 18 individuals examined in the peri-acute phase and 26 controls.

\section{Results}

During the acute phase, participants with transient global amnesia displayed a higher level of anxiety and a more depressed mood than controls. An alteration of emotional state, as measured by the Adjective Mood scale, was correlated with deficits in anterograde memory.

\section{Conclusions}

Transient global amnesia comprises sudden changes in people's emotional state, which has a major impact on and interacts with episodic memory impairment.

\section{Declaration of interest}

None. Funding detailed in Acknowledgements.
Transient global amnesia is a time-limited memory disorder that is characterised by the sudden onset of massive anterograde amnesia, usually accompanied by variable retrograde amnesia. Several studies ${ }^{1,2}$ have stressed the frequent reporting by individuals of emotional precipitants, i.e. intense and personal emotional incidents occurring just before the episode. Others highlighted the presence of psychopathological disorders such as agoraphobic personality traits, and symptoms of depression or panic attack. $^{2-4}$ The first aim of the present study was to establish whether anxiety and mood disorders intervene before (i.e. play a role as predisposing factors) and/or during the episode (i.e. can be considered as one of its symptoms). To gain a better understanding of the role of these psychopathological factors, we studied the putative influence of anxiety and mood disorders on memory impairment observed during transient global amnesia.

\section{Method}

\section{Participants}

Ours is the largest ever neuropsychological study of participants experiencing a transient global amnesia episode. Between 2005 and 2007, 35 people with transient global amnesia were admitted to the emergency department of Caen University Hospital. The selection of participants was systematically carried out by senior neurologists, in line with a codified procedure. The clinical and neurological examinations of the individuals were all normal, except for memory disturbance. Brain computed tomography (CT) scans and electroencephalograms performed during or after the episode were also normal. Seventeen people were examined during the very acute phase. Eighteen others were recruited during the peri-acute phase, i.e. within $24 \mathrm{~h}$ of onset. The exact end of the acute phase is difficult to gauge. ${ }^{2}$ Although the onset of the attack is usually easy to pinpoint because it is so sudden, recovery is gradual and there is no criterion to determine the point at which people start to recover. We estimated the end of the acute phase using several types of clinical data. When individuals still displayed memory disorders but no longer presented temporal disorientation or repetitive questioning, they were included in the peri-acute phase group. People in both groups (acute and peri-acute phases) were matched according to age and level of education (Table 1). All of them fulfilled the criteria for transient global amnesia, ${ }^{5}$ and for six of them, the witness was present for much of the attack but not at the very beginning. In order to list precipitants, i.e. unusual events preceding the attack, we used questionnaires previously described in Quinette et al. ${ }^{2}$ We systematically looked for the presence of risk factors that have previously been reported in the literature and which could supply information on the aetiology of such episodes (Table 1). A control group consisted of 26 strictly selected healthy people, matched with the two case groups according to age (control group mean age: 60.2 years (s.d.=7.3) and level of education (control group mean: 11.8 years $($ s.d. $=3.7)$ ).

All participants gave informed consent to the study, which was performed in compliance with the Declaration of Helsinki. This study was approved by the local ethical committee.

\section{Psychopathological assessments}

In order to determine whether anxiety and mood disorders could be considered to be predisposing factors, participants completed, the day after the episode, two questionnaires assessing anxious personality trait (State-Trait Anxiety Inventory (STAI) $)^{6}$ and the presence of a depressive state at least 2 weeks before the episode (abridged version of the Beck Depression Inventory (BDI) composed of 13 items). ${ }^{7}$ Two other psychopathological scales completed during the attack allowed us to measure the level of anxiety (first part of STAI) and depression (Adjective Mood Scale (or Befindlichkeits-Skala)), ${ }^{8}$ and to determine whether these disorders could be regarded as symptoms specific to this episode. 


\begin{tabular}{|c|c|c|}
\hline & Acute phase $(n=17)$ & Peri-acute phase $(n=18)$ \\
\hline Gender, women/men & $8 / 9$ & 9/9 \\
\hline Age, years: mean (s.d.) & $62.8(6.3)$ & $60.3(9)$ \\
\hline Level of education, years: mean (s.d.) & $10.9(3.4)$ & $9.9(3.7)$ \\
\hline Duration, h: mean (s.d.) & $7.6(1.7)$ & $3.7(3.1)$ \\
\hline Start of examination, h: mean (s.d. $)^{a}$ & $4.8(1.5)$ & $10.7(7.5)$ \\
\hline Recurrences, $n$ & 4 (second episode) + 1 (third episode) & 2 (second episode) \\
\hline \multicolumn{3}{|l|}{ Precipitants, $n$} \\
\hline Stressful event & 4 & 5 \\
\hline Physical effort ${ }^{b}$ & 8 & 4 \\
\hline Intercourse & 1 & 4 \\
\hline Water contact & 1 & 1 \\
\hline No precipitant & 3 & 4 \\
\hline \multicolumn{3}{|l|}{ Risk factors, $n$} \\
\hline Transient ischaemic attack & 1 & 0 \\
\hline High blood pressure & 8 & 7 \\
\hline Hypercholesterolemia & 12 & 4 \\
\hline Diabetes & 3 & 0 \\
\hline Heart disease & 1 & 0 \\
\hline Migraine & 2 & 4 \\
\hline Psychiatric disorders ${ }^{\mathrm{C}}$ & 3 & 7 \\
\hline $\begin{array}{l}\text { a. Number of hours between onset of amnes } \\
\text { b. This category included activities such as g } \\
\text { c. Psychiatric disorders were sought in medi } \\
\text { person. }\end{array}$ & $\begin{array}{l}\text { of neuropsychological examination. } \\
\text { edge and sport. } \\
\text { d previous episodes of depression in eight pec }\end{array}$ & e person and a suicide attempt in one \\
\hline
\end{tabular}

Because transient global amnesia is a short-lived syndrome, we chose scales that did not take long to complete. Because we also thought that moods before and during the episode might be radically different, we used the Adjective Mood Scale, which was designed to measure brief variations in mood. This scale is a particularly sensitive measure of changes in depressive symptomatology and is correlated with other depression scales such as BDI. ${ }^{9}$

The Adjective Mood Scale has already been used to determine the links between current mood state and neuropsychological disorders, notably in psychogenic amnesia. ${ }^{10}$ In this scale, participants must choose between two contrasting adjectives, selecting the one which best characterises them at the time of the test. Another kind of answer is possible if neither adjective is relevant. According to the score, people are classified as relaxed (mean score 12.02), worried (mean score 19.32) or utterly depressed (mean score 34.40 ). The maximal score is 56 .

\section{Neuropsychological assessment}

\section{General cognitive function}

General cognitive assessment consisted of an assessment of orientation and general knowledge. To this end, we used sub-tests taken from the Mattis Dementia Rating Scale, including spatiotemporal orientation, a semantic categorisation task and a categorical fluency task. ${ }^{11}$

\section{Anterograde component of episodic memory}

A recognition task was specially designed to assess the anterograde component of episodic memory. One hundred and thirty-six healthy adults, aged 50-91 years, were divided into six groups, with each processing 96 words taken from a database containing a total of 576 words (assessment of each word by about 20 participants). They evaluated the emotional valence of the words on a Likert-type rating scale ranging from 1 (the most negative) to 8 (the most positive). We obtained 133 negative, 157 positive and 285 neutral words, with mean scores of 2.62 (s.d. $=0.63$ ),
6.36 (s.d=0.56) and 4.89 (s.d.=0.59) respectively. In this test, we selected the 40 most representative words in each category, i.e. 40 negative (mean score 2.42 (s.d. $=0.51$ )), 40 positive (mean score 6.67 (s.d.=0.48)) and 40 neutral (mean score 4.71 (s.d.=0.24)). This produced four lists of 10 words for each valence (matched for word frequency, word length and level of concreteness), ${ }^{12}$ which were used either as a target or a lure to counteract any list effect. For the task itself, we only selected two of the four lists, one as a target and one as a lure.

During the study session, individuals had to memorise a list of 10 positive, 10 negative and 10 neutral words (intentional encoding) and judge the emotional valence of these 30 words on an 8point scale (from $1=$ highly negative to $8=$ highly positive). The test session took place $5 \mathrm{~min}$ later (the interval was filled with a working memory task). Retrieval was assessed by means of a dual forced-recognition task. To assess the state of consciousness associated with each response, we used the Remember/Know/ Guess (R/K/G) paradigm. ${ }^{13}$ A Remember judgement meant that participants re-lived the learning context (i.e. thoughts, feelings or perceptions) and a Know judgement corresponded to a feeling of familiarity in the absence of recollection. A third response was possible if participants were unsure (Guess judgement).

One emotional judgement score (study session) and one recognition score (accuracy) were obtained for each valence list. The measure of accuracy corresponded to $\mathrm{A}^{\prime}$, calculated according to the following formula: ${ }^{13} \mathrm{~A}^{\prime}=1 / 2+[[($ Hit - Falm alarm (FA) $)(1+$ Hit - FA) $] / 4$ Hit $(1-$ FA) $]$. We also calculated recollection and familiarity scores using the number of Remember (R) and Know $(\mathrm{K})$ responses in the following formula: ${ }^{14}$ Recollection=R/ 15 (maximum number of correct $\mathrm{R}$ responses) and Familiarity $=(\mathrm{K} / 15) /(1-$ recollection score $)$.

The task was validated in a preliminary study ${ }^{15}$ carried out in another sample of people examined after a transient global amnesia episode. This prompted us to shorten the initial paradigm in order to adapt it to the examination of individuals during the acute phase. 


\section{Retrograde component of episodic memory}

The autobiographical memory task, derived from Piolino et als semi-structured questionnaire (TEMPau task), ${ }^{16}$ allowed us to gauge ability to recall specific, detailed events situated in time and space from three lifetime periods (18-30 years old, past 10 years except the past 12 months, and past 12 months). We gave a very precise definition of a specific event, that is, a unique event lasting less than a day, located in time and space, which can be recalled with sensory, perceptual or affective details. Two specific memories were requested for each lifetime period (randomly presented on a screen). After each production, participants were asked to judge whether they had re-lived the evoked memory (i.e. recollection) by means of a 6-point scale derived from the Remember/Know paradigm (from a simple feeling of familiarity to a genuine impression of re-experiencing the past event). Lastly, we investigated the emotion associated with the memory, by asking individuals to rate, on two 6-point scales, the intensity (from $1=$ low intensity to $6=$ high intensity) and valence (from $1=$ unpleasant to $6=$ pleasant) of each recalled event.

Four scores were collected for each period. To start, the specificity of each event was scored on a 5-point scale (specificity score). A memory for a unique event that had occurred on a particular day was scored 4 or 3 points, depending on how detailed it was. A memory for a repeated or extended event was scored 2 or 1 , depending on how detailed it was, while general information was scored 0 . We also used a score assessing recollection capacity (recollection score) and two scores measuring the emotional characteristics of the recollection (intensity and valence scores) on the basis of the scales described above (see Piolino et al for more details). ${ }^{17}$ This task was also validated in the above-mentioned preliminary study. ${ }^{15}$

\section{Working memory}

The working memory assessment comprised five tasks used to explore the three components of Baddeley's theoretical framework. ${ }^{18}$ The phonological loop was tested by the forward digit span $\operatorname{task}^{19}$ and the visuospatial sketchpad was assessed by means of the forward visuospatial span task. ${ }^{19}$ Three other tasks focused on the central executive, namely the backward digit and visuospatial spans and the letter/number sequence task (Wechsler Adult Intelligence Scale-III). ${ }^{20}$

\section{Statistical analysis}

We compared the levels of anxiety and depression, and the cognitive performances of all three groups of participants: individuals examined in the acute and peri-acute phases of transient global amnesia and controls. Data were analysed using a one-way analysis of variance (ANOVA), with group as a between-participant factor. Post hoc analyses (Tukey test) were then used to conduct paired comparisons of group performances.
To determine the influence of psychological factors on memory disorders, we established correlations between the participants with scores on the psychopathological scales and their cognitive performances. To increase the statistical power, we considered all these participants as a single group ( 35 individuals) and reduced the number of cognitive variables, selecting the most representative and independent impaired cognitive scores on each task. A probability level of 0.05 was adopted for all analyses.

\section{Results}

\section{Psychopathological deficits}

There was no significant difference between the three groups for the scores on the trait-STAI $(F(2,58)=1.07, P=0.35)$ and BDI $(F(2,58)<1)$, although there was one difference for the scores on the state-STAI $(F(2,34)=4.70, P=0.01)$ and the Adjective Mood Scale $(F(2,56)=11.82, P<0.001)$ (Table 2$)$. The post hoc analysis revealed that only participants examined in the acute phase obtained higher scores than controls. There was no significant difference between those observed in the peri-acute phase and controls. There was no difference in the scores between the two groups with transient global amnesia.

\section{Effect of psychopathological disorders on memory impairments}

Neuropsychological assessment

General cognitive functions (online Table DS1). There was a significant group effect for the orientation sub-test $(F(2,58)=17.47, P<0.001)$. A post hoc analysis revealed that only individuals examined in the acute phase were disoriented. Results of the semantic categorisation task were normal $(F(2,58)<1)$. The number of correct responses and perseverative errors on the categorical fluency task $(F(2,58)=10.99, P<0.01$ and $F(2,58)=12.93$, $P<0.001$ respectively) differed significantly between the three groups. The acute and peri-acute groups provided fewer correct responses than controls. The number of perseverative errors was higher in individuals in the acute phase group than in the periacute phase and control groups.

Anterograde component of episodic memory (online Table DS1). There was no significant difference between the three groups in the emotional judgement scores, whatever the valence (positive words $F(2,56)<1$; negative words $F(2,56)=1.13$; $P=0.33$; and neutral words $F(2,56)<1$ ). Thus, the words' emotional valence was correctly identified by all people with transient global amnesia.

When we analysed the accuracy scores ( $\mathrm{A}^{\prime}$ score calculated from the number of hits and false alarms) for each emotional valence, we found a significant group effect on the accuracy scores for positive words $(F(2,58)=56.40, P<0.001)$, negative words $(F(2,58)=69.16, P<0.001)$ and neutral words $(F(2,58)=114.35$,

\begin{tabular}{|c|c|c|c|}
\hline & Acute phase ( $n=17)$, mean (s.d.) & Peri-acute phase ( $n=18)$, mean (s.d.) & Controls $(n=26)$, mean (s.d.) \\
\hline Trait STAI & $44.2(8.7)$ & $50.0(11.7)$ & $46.3(9.4)$ \\
\hline Short version of BDI & $2.6(3)$ & 3.1 (3.6) & $2.5(2.4)$ \\
\hline State STAl ${ }^{\mathrm{a}}$ & $59.3(11.3)^{\star *}$ & $51.4(16.3)$ & $44.7(6.5)$ \\
\hline Adjective Mood Scale & $23.9(8.5)^{\star * *}$ & $16.9(9.2)$ & $10.8(7.8)$ \\
\hline
\end{tabular}


$P<0.001)$. The post hoc analyses revealed that individuals examined in the acute and peri-acute phases had significantly lower performances than controls, whatever the valence. Moreover, people examined in the acute phase obtained lower accuracy scores than those observed in the peri-acute phase, whatever the valence.

An analysis of the recollection scores for each valence revealed a significant group effect on the recollection scores for positive items $(F(2,58)=149.49, P<0.001)$, negative items $(F(2,58)=79.99$, $P<0.001)$ and neutral items $(F(2,58)=44.92, P<0.001)$. Thus, whatever the valence, recollection scores were lower in individuals with transient global amnesia examined in the acute phase than in those observed in the peri-acute phase and in controls. In turn, all the recollection scores (regardless of valence) of individuals with transient global amnesia observed in the peri-acute phase were lower than those of the controls.

Lastly, we found a significant group effect on familiarity scores for positive items $(F(2,58)=5.32, \quad P<0.01)$, negative items $(F(2,58)=3.10, \quad P=0.05)$ and neutral items $(F(2,58)=6.61$, $P<0.01)$. Participants with transient global amnesia examined in the acute phase had lower scores than controls for positive and neutral items, but not for negative items. There was no significant effect on familiarity scores between those observed in the peri-acute phase and controls, whatever the valence. There was no difference between the acute and peri-acute groups for familiarity scores.

Retrograde component of episodic memory (online Table DS1). First, we conducted an analysis of the specificity scores for each lifetime period. We found a significant group effect on score for each lifetime period: $18-30$ years old $(F(2,57)=9.57$, $P<0.001)$, the past 10 years $(F(2,57)=11.30, P<0.001)$ and the past 12 months $(F(2,57)=15.29, P<0.001)$. More specifically, individuals examined in the acute phase supplied fewer episodic memories than controls, whatever the lifetime period. There was no significant effect between the acute and peri-acute groups. A significant effect was found between participants observed in the peri-acute phase and controls for the past 10 -year and past 12 month periods.

As far as the recollection score was concerned, analyses failed to reveal any significant group effect for the 18- to 30-year-old period $(F(2,57)=2.50, \quad P=0.09)$ or the past 10 -year period $(F(2,57)=3.35, P=0.10)$. There was, however, a significant group effect on this score for the most recent lifetime period $(F(2,57)=9.64, P<0.001)$. Specifically, participants examined in the acute phase showed a reduction in recollection capacities, compared with those observed in the peri-acute phase and in controls.

There was no group effect on the intensity scores for the 18- to 30 -year-old $(F(2,57)=1.04, P=0.36)$ and the past 10 -year periods $(\mathrm{F}(2,57)=1.36, P=0.26)$. A significant difference between all three groups was highlighted for the intensity scores of the most recent period, i.e. the past 12 months $(F(2,57)=4.77, P=0.01)$. The post hoc analysis showed that individuals examined in the acute phase supplied less intense memories than controls. Other comparisons based on post hoc tests were not significant. We found the same pattern of results for valence scores. Although the valence scores for the 18- to 30-year-old and past 10-year periods did not significantly differ between the three groups $(F(2,57)<1$ and $F(2,57)=1.84, P=0.18$ respectively), there was a significant group effect on the valence score for the past 12-month period $(F(2,57)=3.33, P=0.04)$. The post hoc analysis revealed that only participants examined in the acute phase supplied more negative memories than controls.

Working memory (online Table DS1). No statistical difference between the three groups was found for performances on the forward and backward digit span $(F(2,58)=2.21, \quad P=0.12$ and $F(2,58)=2.09, P=0.13$ respectively) and forward visuospatial span tasks $(F(2,55)=2.06, P=0.14)$. However, there was a significant group effect for the backward visuospatial span $(F(2,55)=3.59$, $P=0.03)$ and letter/number sequence tasks $(F(2,58)=6.68$ $P<0.01)$. Post hoc analyses showed that only participants examined in the acute phase performed more poorly than controls on both tasks.

\section{Correlations between psychopathological and neuropsychological scores}

We found a significant negative correlation between the trait anxiety score and the number of words produced in the fluency task. There are also significant negative correlations between the score on the Adjective Mood Scale and the three accuracy scores. All the correlations are reported in Table 3.

\section{Discussion}

The results of this study show that transient global amnesia comprises not only memory impairment but also acute changes in mood and anxiety levels. Moreover, these modifications of emotional state affect cognitive performances. Our findings are

Table 3 Correlations between psychopathological scales and impaired neuropsychological scores in participants with transient global amnesia $(n=35)$

\begin{tabular}{|c|c|c|c|c|}
\hline & State anxiety ${ }^{a}$ & Trait anxiety & BDI & Adjective Mood Scale ${ }^{a}$ \\
\hline Categorical fluency & -0.18 & $-0.46 * *$ & -0.19 & -0.16 \\
\hline \multicolumn{5}{|c|}{ Accuracy scores (assessment of anterograde amnesia) } \\
\hline Positive items & -0.35 & +0.15 & -0.04 & $-0.38^{*}$ \\
\hline Negative items & -0.19 & +0.27 & -0.17 & $-0.37^{\star}$ \\
\hline Neutral items & -0.38 & +0.19 & -0.03 & $-0.41^{*}$ \\
\hline \multicolumn{5}{|c|}{ Specificity scores (assessment of retrograde amnesia) } \\
\hline Life period: $18-30$ years & +0.32 & +0.06 & +0.17 & +0.03 \\
\hline Life period: past 10 years & -0.12 & -0.24 & -0.05 & -0.32 \\
\hline Life period: past 12 months & +0.05 & -0.13 & -0.09 & -0.04 \\
\hline \multicolumn{5}{|l|}{ Working memory } \\
\hline Backward visuospatial span & +0.04 & +0.20 & +0.04 & -0.14 \\
\hline Letter-number sequence & +0.06 & -0.20 & -0.03 & -0.06 \\
\hline \multicolumn{5}{|c|}{$\begin{array}{l}\text { BDI, Beck Depression Inventory. } \\
\text { a. Missing data: correlations with state anxiety on the State-Trait Anxiety Inventory carried out in } 22 \text { people with transient global amnesia; correlations with mood carried out in } 34 \\
\text { people with transient global amnesia. }\end{array}$} \\
\hline
\end{tabular}


discussed in two parts: psychopathological disorders observed in the acute and peri-acute phases; and the influence of these psychopathological disorders on the neuropsychological profile of transient global amnesia.

\section{Psychopathological disorders}

Not only did almost all the participants with transient global amnesia display a sudden change in mood and anxiety levels during the episode, but these modifications of emotional state also followed the dynamic of the episode. As with memory disorders, we observed a deterioration in the emotional state during the acute phase, which subsequently improved during the peri-acute phase. These results suggest that the changes in mood and anxiety levels during the episode can be considered as symptoms. Clinical descriptions of individuals in the past have emphasised their particular emotional state: anxious attitude (verbal leitmotifs linked with their worry), tears, symptoms similar to those of a panic attack. ${ }^{4}$ One possible explanation may be that transient global amnesia shares some physiopathological characteristics with anxiety and mood disorders. In addition to transitory hippocampal dysfunction, it is often associated with hypoperfusion or hypometabolism of the amygdale ${ }^{21}$ or frontal regions, ${ }^{22}$ which are also implicated in anxiety and mood disorders. ${ }^{23}$ The results of the group analysis of the scores on the two scales measuring the presence of trait anxiety and depressive symptoms prior to the episode show that the acute and peri-acute groups and controls obtained similar scores. This suggests that the anxiety personality trait and depressive symptoms are not predisposing factors for an episode. At first sight, these results would appear to contradict those of our previous study. ${ }^{2}$ However, when we carried out individual analyses, we found that 16 of the 35 participants with transient global amnesia displayed a high level of anxiety (i.e. a score above 50 on the STAI) ${ }^{6}$ and 5 of them showed depressed symptoms (i.e. a score above 8 on the abridged version of the BDI). ${ }^{7}$ Thus, the presence of these symptoms in some participants with transient global amnesia before the episode (and this was corroborated by relatives) could also have influenced the psychopathological and neuropsychological profiles of some individuals. However, we cannot completely exclude the possibility that the experience of an episode changed the self-judgement of people on the emotional state they felt during the days preceding it, meaning that this assessment would reflect the current rather than the previous emotional state.

\section{Influence of psychopathological disorders on neuropsychological profile}

First, we have highlighted a massive impairment of episodic memory associated with a slight executive deficit. During the peri-acute phase, these disorders decreased, but participants with transient global amnesia still displayed disturbances, especially of episodic memory.

During the acute phase, anterograde amnesia was characterised by a low recognition rate of items, whatever the emotional valence of these items. Moreover, even when participants did recognise items correctly, their responses were based solely on a feeling of uncertainty (Guess responses). The absence of both Remember and Know responses reflected the extent of their anterograde amnesia. During the peri-acute phase, even though individuals' performances improved, recognition was still disturbed. In particular, participants supplied fewer Remember responses than controls during the peri-acute phase; they had a considerable recollection deficit, although they were able to use the familiarity process (Know responses) as effectively as controls. Thus, even if performances improved, these relied more on semantic memory (feeling of familiarity) than on the residual capacities of episodic memory.

Regarding retrograde amnesia, our results confirmed that memories retrieved by those with transient global amnesia are neither specific nor detailed during the episode. ${ }^{24}$ The decline of retrograde amnesia was characterised by the recovery of memories from all but the most recent periods. This recovery of memories in chronological order, in accordance with Ribot's Law, ${ }^{25}$ has already been demonstrated in transient global amnesia ${ }^{26}$ and other memory disorders. ${ }^{27}$

Our results also suggest minor impairment of executive functions. Contrary to the phonological loop and the visuospatial sketchpad, the central executive of working memory was impaired during the episode. In a previous study, ${ }^{28}$ we highlighted an abnormally rapid loss of verbal and visuospatial information when rehearsal was prevented. This explains why we found pathological scores on tasks that involved both the storage and handling of information. Moreover, the presence of another executive deficit, observed during the acute and peri-acute phases, was emphasised by the decreased production of responses on the categorical fluency task, which has previously been interpreted as an impairment of semantic memory retrieval strategies. ${ }^{29}$ This disturbance probably did not reflect a semantic memory disorder, as demonstrated by the preservation of conceptual knowledge we observed during an episode. ${ }^{30}$

Second, we showed that cognitive performances were indeed affected by psychopathological disorders, as shown by significant correlations between accuracy scores and scores on the Adjective Mood Scale. However, although participants with transient global amnesia displayed a high level of anxiety at the time of the episode, this did not greatly affect neuropsychological disorders. Anxiety only contributed to the deficit in word production in the categorical fluency task. This impairment, which can be ascribed to impaired retrieval strategies in semantic memory, has also been observed in anxiety disorders ${ }^{31}$ and can be linked to frontal lobe activity. ${ }^{32}$ This reinforces the hypothesis that the deficit in production was because of the disruption of executive functions, at least in the more anxious individuals. Conversely, depressed mood disorders were found to influence memory performances: there was a deleterious effect of depressed emotion on memory that mainly concerned the anterograde component of episodic memory. We showed that the more pathological the scores assessing the current mood state, the poorer the recognition performances, whatever the valence of the items. This effect of depressed mood has also been observed in people with clinical or non-clinical depression, ${ }^{33}$ as in experimental negative mood induction, ${ }^{34}$ and could be explained by a depletion in attentional resources due to interfering activities. ${ }^{35}$ A negative mood state is characterised by irrelevant thoughts which are in keeping with depressed emotion and which interfere with cognitive tasks. ${ }^{36}$ Moreover, this aversive effect of negative mood state on cognitive performances would appear to be greater in elderly people than in young adults. ${ }^{37}$ It may be a similar story for the verbal leitmotifs (often linked to worries) that are observed in transient global amnesia. Regarding retrograde amnesia, neither the participants' mood nor their anxiety level affected their ability to evoke episodic memories.

As almost all participants with transient global amnesia displayed a depressed mood state, we expected to observe greater processing of negative items in the recognition task and preferential production of negative memories in the autobiographical tasks, as has already been reported for depression. ${ }^{38}$ Although this mood congruency effect was not actually observed in the recognition task, it may have been masked by the extensive anterograde amnesia. We did, however, find a mood congruency effect in the task assessing the retrograde component of episodic memory: 
participants with transient global amnesia supplied more negative memories than controls for the most recent life period, which was also the one most adversely affected by an episode.

\section{Clinical implications and limitations of the study}

Transient global amnesia causes a deterioration of mood and an increasing level of anxiety during an episode. These modifications of mood have a deleterious effect on memory performances. During the acute phase, the management of anxiety both in individuals experiencing an episode and relatives should be based on verbal reassurance. ${ }^{39}$ Concerning subclinical depression observed, other studies should be carried out to determine whether these individuals need short-term treatment. A followup study could supply further information on the psychological impact of the episode on everyday life. For relatives, medical staff must stress that transient global amnesia is a benign condition, and that the work-up is only intended to rule out more serious diseases such as stroke or epilepsy. Family members should also be reassured to prevent their anxiety from increasing that of their relatives with amnesia. Finally, as anxiety is more frequent in idiopathic than post-traumatic transient global amnesia, this symptom might be used as a diagnostic clue to distinguish both conditions when information about the start of the episode is lacking, but this needs to be confirmed in further studies.

We cannot exclude the possibility that psychopathological disorders present in some individuals before the episode also influenced memory performances. The evolution of these psychopathological disorders in the time course of the episode was not examined.

In conclusion, we recorded high anxiety levels and a depressed mood state during an episode. Trait but not state anxiety was correlated with categorical fluency, and transiently depressed mood was associated with impaired anterograde memory performances. Other studies have stressed the link between emotional precipitants and the onset of transient global amnesia and reported the presence of psychopathological disorders in some people before the episode, ${ }^{2}$ suggesting that psychopathological disorders may constitute one of the predisposing factors for an episode. Other studies are therefore needed in order to explore in greater depth the role of emotional factors in transient global amnesia.

\footnotetext{
Audrey Noël, PhD, Peggy Quinette, PhD, Bérengère Guillery-Girard, PhD, Inserm - EPHE - Université de Caen Basse-Normandie, Caen; Jacques Dayan, MD, PhD Département de Psychiatrie de I'Enfant et de I'Adolescent, CHR Clémenceau, and Inserm - EPHE - Université de Caen Basse-Normandie, Caen; Pascale Piolino, PhD, Université Paris Descartes - CNRS, Laboratoire Psychologie et Neurosciences Cognitives, Paris, and Inserm - EPHE - Université de Caen Basse-Normandie, Caen; Sophie Marquis, MD, Département d'Accueil et de Traitement des Urgences, Caen University Hospital Côte de Nacre, Caen; Vincent de la Sayette, MD, Fausto Viader, MD, Département de Neurologie, Caen University Hospital Côte de Nacre, Viader, MD, Département de Neurologie, Caen University Hospital Côte de Nacre
and Inserm - EPHE - Université de Caen Basse-Normandie, Caen; Béatrice and Inserm - EPHE - Université de Caen Basse-Normandie, Caen; Béatrice
Desgranges, PhD, Francis Eustache, PhD, Inserm - EPHE - Université de Caen Basse-Normandie, Caen, France.

Correspondence: Francis Eustache, Inserm - EPHE - Université de Caen Basse-Normandie, Unité U923, Laboratoire de Neuropsychologie, Caen University Hospital Côte de Nacre, 14033 Caen Cedex, France. Email: neuropsycho@chu-caen.fr

First received 26 Sep 2007, final revision 26 Feb 2008, accepted 26 Mar 2008
}

\section{Acknowledgements}

We thank Caen University Hospital, who funded this study as part of a clinical research project, and the Servier Laboratory for its financial help.

\section{References}

1 Merriam AE, Wyszynski B, Betzler T. Emotional arousal-induced transient global amnesia. A clue to the neural transcription of emotion? Psychosomatics 1992; 33: 109-13.
2 Quinette P, Guillery-Girard B, Dayan J, de la Sayette V, Marquis S, Viader F, Desgranges B, Eustache $\mathrm{F}$. What does transient global amnesia really mean? Review of the literature and thorough study of 142 cases. Brain 2006; 129 : 1640-58.

3 Neri M, Andermarcher E, De Vreese LP, Rubichi S, Sacchet C, Cipolli C. Transient global amnesia: memory and metamemory. Aging 1995; 7: 423-9.

4 Inzitari D, Pantoni L, Lamassa M, Pallanti S, Pracucci G, Marini P. Emotional arousal and phobia in transient global amnesia. Arch Neurol 1997; 54: $866-73$.

5 Hodges JR, Warlow CP. Syndromes of transient amnesia: towards a classification. A study of 153 cases. J Neurl Neurosurg Psychiatry 1990; 53: 834-43.

6 Spielberger CD. Manual for the State-Trait Anxiety. Consulting Psychologist Press, 1983.

7 Beck AT, Rial WY, Rickets K. Short form of Depression Inventory: cross validation. Psychol Reports 1974; 34: 1184-6.

8 Von Zerssen D, Koeller DM, Rey ER. A scale for the objective evaluation of the state of subjective well-being as a method for longitudinal studies. Arzneimittelforschung 1970; 20: 915-8.

9 Moller HJ. Rating depressed patients: observer- vs self-assessment. Eur Psychiatry 2000; 15: 160-72.

10 Markowitsch HJ, Kessler J, Russ MO, Frolich L, Schneider B, Maurer K. Mnestic block syndrome. Cortex 1999; 35: 219-30.

11 Mattis S. Mental statut examination for organic mental syndrome in the elderly patient. In Geriatric Psychiatry: A Handbook for Psychiatrics and Primary Care Physicians (eds L Bellack \& T Katasu): 77-120. Grune \& Stratton, 1976.

12 New B, Pallier C, Ferrand L, Matos R. Une base de données lexicales du français contemporain sur internet: lexique. Année Psychol 2001; 101: $447-62$.

13 Gardiner JM, Ramponi C, Richardson-Klavehn A. Recognition memory and decision processes: a meta-analysis of remember, know, and guess responses. Memory 2002; 10: 83-98.

14 Yonelinas AP, Kroll NE, Dobbins I, Lazzara M, Knight RT. Recollection and familiarity deficits in amnesia: convergence of remember-know, process dissociation, and receiver operating characteristic data. Neuropsychology 1998; 12: 323-39.

15 Noël A, Quinette P, Guillery-Girard B, Dayan J, Katis S, Piolino P, Abadie P, de la Sayette V, Marquis S, Viader F, Desgranges B, Eustache F. How psychopathological factors affect both the onset of and recovery from transient global amnesia. Psychol Med 2007; 20: 1-4.

16 Piolino P, Desgranges B, Belliard S, Matuszewski V, Lalevée C, de la Sayette $\mathrm{V}$, Eustache F. Autobiographical memory and autonoetic consciousness: triple dissociation in neurodegenerative diseases. Brain 2003; 126: 2203-19.

17 Piolino P, Giffard-Quillon G, Desgranges B, Chetelat G, Baron JC, Eustache F. Re-experiencing old memories via hippocampus: a PET study of autobiographical memory. Neuroimage 2004; 22: 1371-83.

18 Baddeley A, Della SS. Working memory and executive control. Philos Trans $R$ SOC Lond B Biol SCi 1996; 351: 1397-403.

19 Wechsler D. Echelle Clinique de Mémoire Révisée. Editions du Centre de Psychologie Appliqué, 1991.

20 Wechsler D. Wechsler Adult Intelligence Scale (3rd edn). The Psychological Corporation, 1997.

21 Guillery B, Desgranges B, de la Sayette V, Landeau B, Eustache F, Baron JC. Transient global amnesia: concomitant episodic memory and positron emission tomography assessment in two additional patients. Neurosci Lett 2002; 325: 62-6.

22 Baron JC, Petit-Taboué MC, Le Doze F, Desgranges B, Ravenel N, Marchal G. Right frontal cortex hypometabolism in transient global amnesia. A PET study. Brain 1994; 117: 545-52.

23 Mayberg HS, Liotti M, Brannan SK, McGinnis S, Mahurin RK, Jerabek PA, Silva JA, Tekell JL, Martin CC, Lancaster JL, Fox PT. Reciprocal limbic-cortical function and negative mood: converging PET findings in depression and normal sadness. Am J Psychiatry 1999; 156: 675-82.

24 Hodges JR, Ward CD. Observations during transient global amnesia. A behavioural and neuropsychological study of five cases. Brain 1989; 112: 595-620.

25 Ribot T. Les maladies de la Mémoire. Éditions Baillères, 1881.

26 Guillery-Girard B, Desgranges B, Urban C, Piolino P, de la Sayette V, Eustache $\mathrm{F}$. The dynamic time course of memory recovery in transient global amnesia. J Neurol Neurosurg Psychiatry 2004; 75: 1532-40.

27 Kopelman MD. Disorders of memory. Brain 2002; 125: 2152-90. 
28 Quinette P, Guillery-Girard B, Noël A, de la Sayette V, Viader F, Desgranges B Eustache $F$. The relationship between working memory and episodic memory disorders in transient global amnesia. Neuropsychologia 2006; 44: 2508-19.

29 Eustache F, Desgranges B, Petit-Taboué MC, de la Sayette V, Piot V, Sablé C Marchal G, Baron JC. Transient global amnesia: implicit/explicit memory dissociation and PET assessment of brain perfusion and oxygen metabolism in the acute stage. J Neurol Neurosurg Psychiatry 1997; 63: 357-67.

30 Hodges JR. Semantic memory and frontal executive function during transient global amnesia. J Neurol Neurosurg Psychiatry 1994; 57: 605-8.

31 Everhart DE, Harrison DW. Heart rate and fluency performance among highand low-anxious men following autonomic stress. Int J Neurosci 2002; 112 1149-71.

32 Thibodeau R, Jorgensen RS, Kim S. Depression, anxiety, and resting frontal EEG asymmetry: a meta-analytic review. J Abnorm Psychol 2006; 115 : 715-29.

33 Airaksinen $\mathrm{E}$, Larsson $\mathrm{M}$, Lundberg I, Forsell $\mathrm{Y}$. Cognitive functions in depressive disorders: evidence from a population-based study. Psychol Med 2004; 34: 83-91.
34 Ellis HC, Thomas RL, MCFarland AD, Lane JW. Emotional mood states and retrieval in episodic memory. J Exp Psychol Learn Mem Cogn 1985; 11: $363-70$.

35 Trask PC, Sigmon S. Ruminating and distracting: the effects of sequential tasks on depressed mood. Cognit Ther Res 1999; 23: 231-46.

36 Seibert PS, Ellis HC. Irrelevant thoughts, emotional mood states, and cognitive task performance. Mem Cognit 1991; 19: 507-13.

37 Deptula D, Singh R, Pomara N. Aging, emotional states, and memory. Am J Psychiatry 1993; 150: 429-34.

38 Ergis AM, Piolino P, Mure C. Explicit and implicit memory for emotional stimuli in depressed elderly and Alzheimer's disease. Psychol Neuropsychiatr Vieil 2003; 1: 265-71.

39 Harrison $\mathrm{M}$, Williams $\mathrm{M}$. The diagnosis and management of transient global amnesia in the emergency department. Emerg Med J 2007; 24: 444-5.

\section{Poems by doctors}

\section{Miroslav Holub}

In laughter we stretch the mouth from ear to ear,

or at least in that direction,

we bare our teeth and in that way reveal

long-past stages in evolution

when laughter still was an expression of

triumph over a slain neighbour.

We expel our breath right up from the throat,

according to need we gently vibrate our

vocal chords, if necessary we also touch our foreheads

or the back of our heads, or we rub our hands or slap

our thighs, and in that way reveal long-past stages

when victory also presupposed

fleetness of foot.

Generally speaking, we laugh when we feel like laughing

In special instances we laugh

when we don't feel like laughing at all,

we laugh because laughter is prescribed or

we laugh because it isn't prescribed.

And so, in effect, we laugh all the time, if only

to conceal the fact that all the time someone

is laughing at us.

Holub, M. (2006) Brief reflection on laughter. In Poems Before and After (transl. I. Milna \& T. Milna). Bloodaxe Books.

Miroslav Holub (1923-1998) was born in Pilsen, western Bohemia. He studied medicine at Charles University in Prague and trained as an immunologist at the Microbiological Institute of the Czechoslovak Academy of Science. He was a successful scientist but is best known for his poetry. His recognition followed the publication in 1967 of Selected Poems as part of Penguin's series on modern European poets. His poetry was proscribed in Czechoslovakia between 1970 and 1980.

Researched by Femi Oyebode. 